\title{
REPLACEMENT OF ARTHRITIC HIPS BY THE MCKEE-FARRAR PROSTHESIS
}

\author{
G. K. McKee and J. Watson-Farrar, Norwich, England
}

The surgical treatment of chronic arthritis of the hip is usually a compromise between the relief of symptoms and the preservation of such function as may remain in the joint. The replacement of both the femoral head and the acetabulum by metal prostheses cemented into the bone gives both relief of pain and the restoration of a useful range of movement.

Because the McMurray osteotomy tends to preserve function as well as to relieve symptoms its main indication is in the patient with early arthritis in whom a good range of hip movement is still present. When movement is already greatly restricted it does little, if anything, to improve function. At the other extreme arthrodesis completely relieves pain, but with total loss of all movement. It remains a useful operation for severe arthritis in the comparatively young, but it has only a limited application in the elderly, especially when the lumbar spine is also arthritic. Thus there is left a very large group of elderly patients with stiff painful hips for whom neither of these well established operations is satisfactory but who will benefit from an arthroplasty.

Replacement of the femoral head by a Thompson or Austin Moore metal prosthesis, although free from the objections of the Judet acrylic head, tackles only one half of the problem unless degenerative changes are confined to the head alone, with a relatively normal acetabulum. Even in these hips, however, it is almost impossible to achieve congruity between the prosthetic head and the acetabulum and the load bearing area in the acetabulum must of necessity be small, with a high load per unit area.

The problem of tackling both sides of the hip joint is met in the Smith-Petersen Vitallium mould arthroplasty, but even this operation in the best hands has only a 45 per cent rate of excellent or good results in the first two years, increasing to 62.5 per cent between eight and twelve years (Law 1962).

\section{DEVELOPMENT OF THE ARTIFICIAL HIP JOINT AT NORWICH}

Since 1951 a replacement ball and socket type of artificial joint has been used at Norwich with a mixed measure of success.

Of the first three appliances two were made of stainless steel and became loose in less than a year; they had to be removed, leaving the patient with a Girdlestone type of pseudarthrosis. The third prosthesis was fixed by chrome-cobalt alloy screws and the ciomponents remained tight. The result was good until the apparatus broke three years later. Ii seemed obvious that the chrome-cobalt alloy had decided advantages over stainless steel.

After a visit to the United States of America in 1953 (G. K. M.) it was decided to use a suitably modified Thompson prosthesis as the femoral component. The modification consisted in having a much smaller head; this articulated with a cup that was screwed into the roof of the acetabulum (Fig. 1). The whole apparatus was made of chrome-cobalt alloy. This prosthesis was used in forty hips between 1956 and 1960 and gave 51 per cent of good or fair results, about the same success rate as the cup arthroplasty operation.

A careful analysis $\mathrm{of}$ these results showed that success depended above all upon the two components of the replacement joint remaining tight within the bone. As long as this was so pain was relieved and function, to a varying extent, was restored. Once one or other component worked loose then pain on weight-bearing occurred.

In 1960 Charnley described the use of methylmethracrylate in order to anchor a Thompson prosthesis within the femoral shaft. This method of fixation opened up new ways in which 
the components of an artificial hip joint could be used. A new acetabular prosthesis was designed. Several variations were tried until the present model, which has been used in over

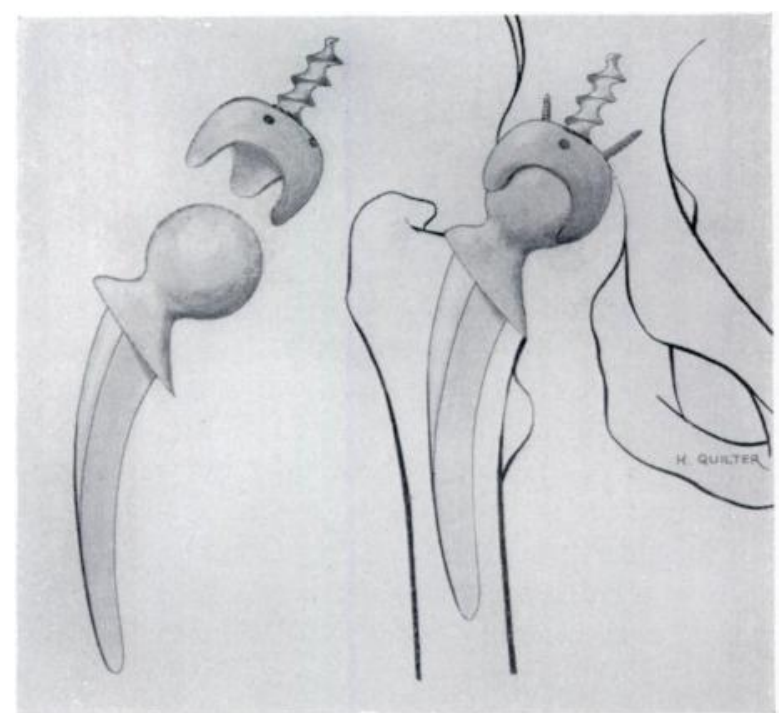

FiG. 1

An early model of an artificial hip joint between 1956 and 1960.

100 hips in the last four years, was developed.

The use of cement to anchor the acetabular component allowed it to be sunk deeply into the acetabulum instead of only being screwed into the roof, as with the previous models. This in turn allowed a standard Thompson prosthesis to be used instead of one with a smaller head.

This combination gave several advantages. First, the joint itself was situated in what was more or less the normal anatomical position and thus the mechanics of the various muscles that act upon the hip were not appreciably altered. This particularly applied to the abductor muscles and obviated the need to transplant the greater trochanter, a procedure that is not without its own difficulties.

Second, the use of a larger head and cup meant that the load of the body on weight bearing was spread over a larger surface area, and that this load, because of the use of the plastic cement, was spread over the whole of the acetabulum. This is considered to be important because it means that no single small area of the acetabulum is subjected to a high load, which might lead to bone destruction.

The theoretical disadvantage of this design was that, with a relatively large head, the frictional resistance must be higher than with a small head and socket. In practice, however. only a small amount of movement is believed to occur between the head and socket when the leg is fully weight bearing and when the frictional forces are at their greatest. Most of the movement that occurs at the hip does so when the leg is not weight bearing, when gravity will tend to distract the joint and this combination of circumstances must considerably reduce friction.

An objection can also be levelled against the use of similar metals on both surfaces of a joint, but experiments at the Royal National Orthopaedic Hospital, Stanmore (Scales 1964), have shown that chrome-cobalt alloy upon chrome-cobalt alloy has a lower coefficient of friction than combinations of other metals; that there is less tendency for them to bond together or "self-weld," and that this alloy wears less than do other metals. Titanium is not suitable as it does tend to bond,

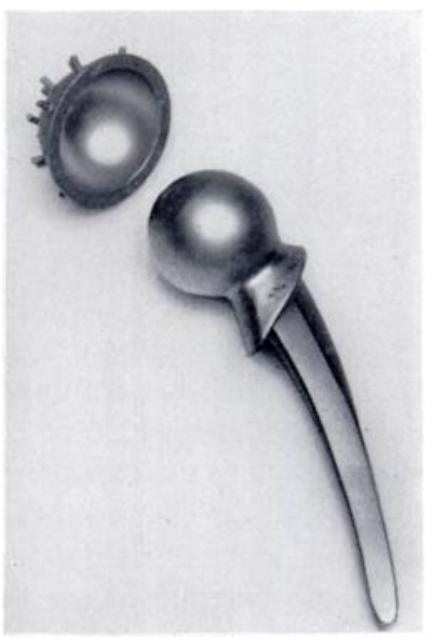

Fig. 2

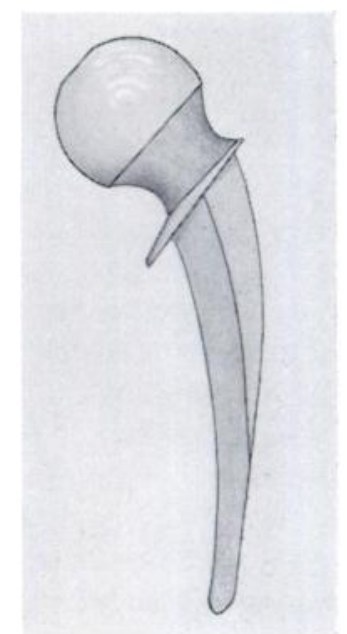

FIG. 3

Figure 2-The model used in this series. Figure 3--The redesigned femoral component. 
and stainless steel is not sufficiently inert. Metal on plastic may give rise to trouble because fine particles rubbed off the plastic are liable to cause tissue irritation and bone absorption. This present model has been in use for four years. Some of the earlier chrome-cobalt alloy upon chrome-cobalt alloy models are still working extremely well after eight years and there thus seems to be no cause to worry about the use of chrome-cobalt alloy for both components of the joint.

Description of the joint-The joint consists of two components, the femoral, which is at present a standard Thompson prosthesis one and five-eighths of an inch in diameter, and the acetabular, which is a hemispherical cup lapped in to fit the head of the Thompson prosthesis. thus forming a pair which should only be used as such (Fig. 2).

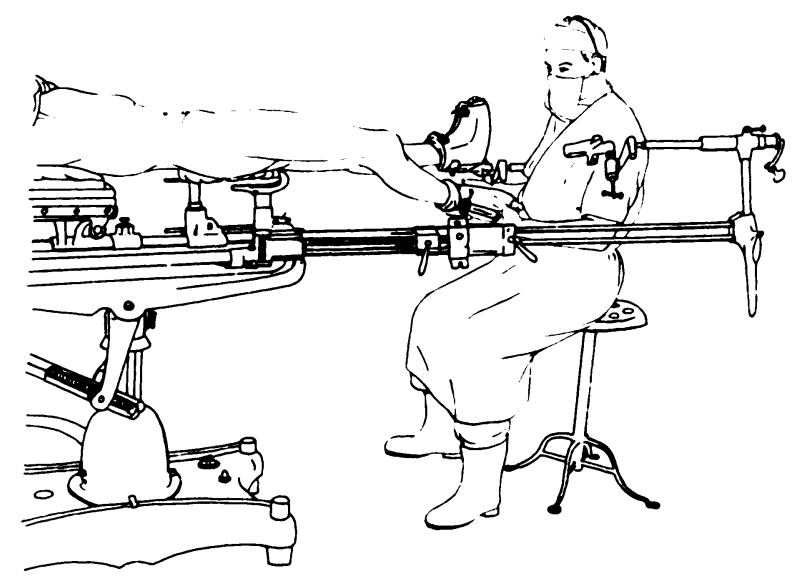

FIG. 4

The position of the patient on the orthopaedic table and of the unsterile assistant controlling the leg.

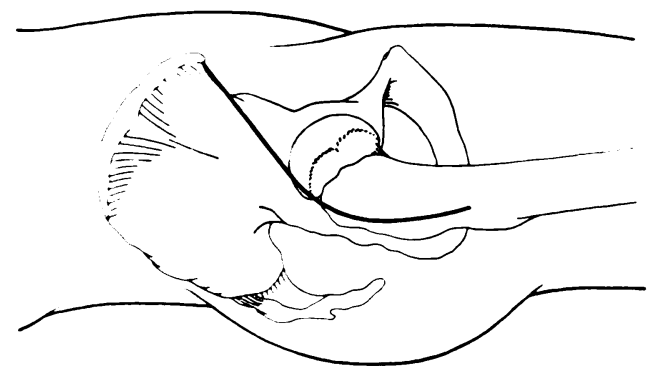

FIG. 5

The incision for the antero-lateral approach.

The edge of the cup has a lip; this not only reinforces it but helps to prevent the plastic cement from overflowing into the cup. The outer surface is covered with small studs which give the cup a positive hold when it is embedded in the plastic; they also ensure that the cement is of adequate thickness.

There are two essential features to this joint. First, both components must be constructed of chrome-cobalt alloy for the reasons that have already been mentioned, namely low frictional resistance, the least wear and complete lack of any reaction by the body tissues to this metal. Second, the joint must be a perfect fit because this reduces the amount of wear that will occur within the body. To ensure this each joint is individually lapped in so that a perfect pair is formed and a specific cup will not necessarily match up with a Thompson head other than the one which was used for the lapping-in process. Both components are stamped with a corresponding number to ensure that they are correctly paired. It is of interest that a standard 
Thompson prosthesis is not truly spherical and has to be made so in the course of the manufacture of this joint.

A further modification was introduced recently; previously the neck of the Thompson prosthesis was deepened by burring it slightly, especially on the inferior part, to allow flexion

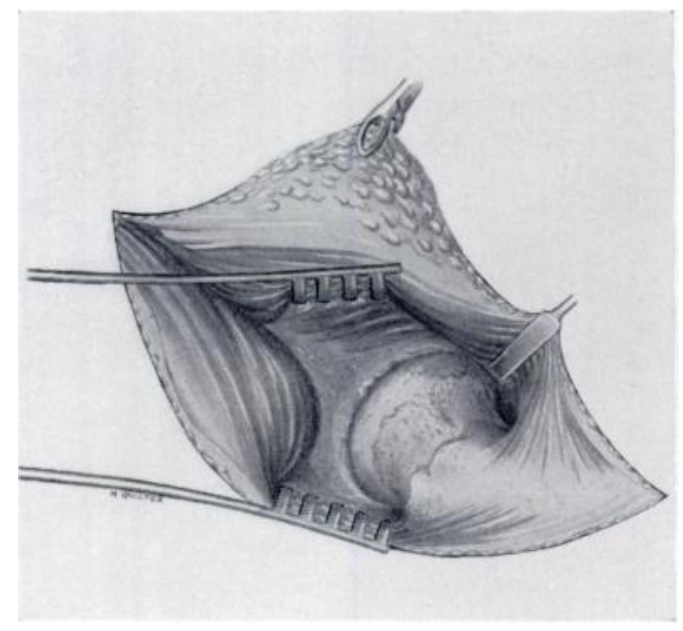

Fig. 6

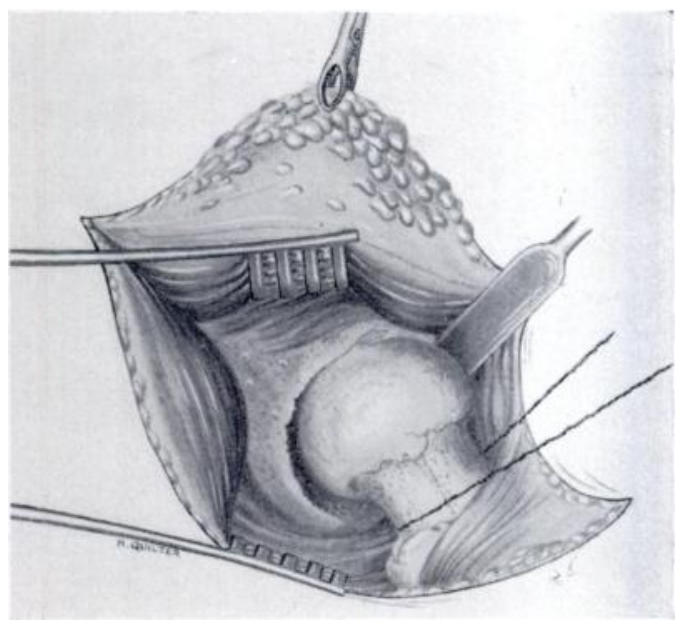

Fig. 7

Figure 6-The approach is between the muscles: here the capsule of the hip joint has been removed. Figure 7 The head of the femur has been dislocated and the Gigli saw is in place to cut through the neck.

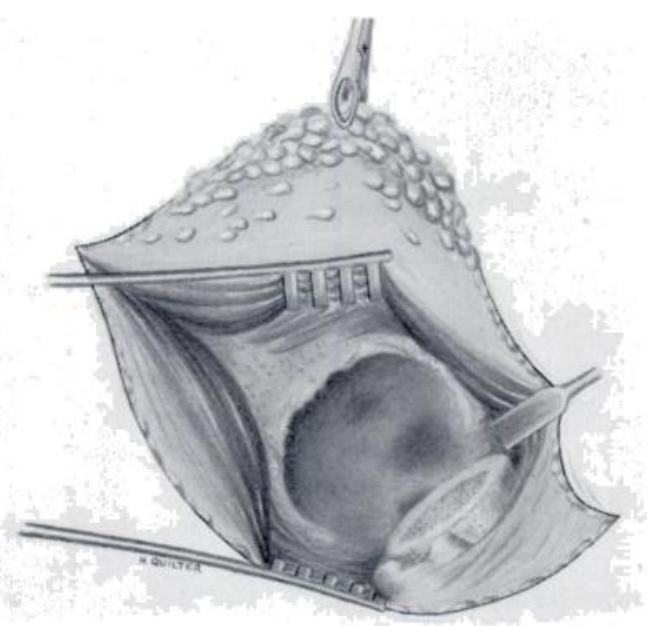

FIG. 8

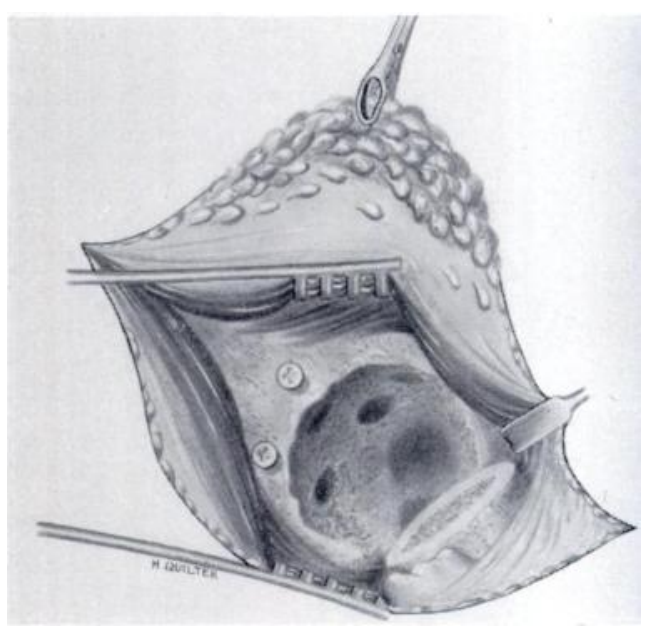

FIG. 9

Figure 8-The exposure of acetabulum after removal of the head of the femur. Figure 9-The acetabulum has been denuded of cartilage, the drill holes have been made and the screws have been inserted.

to occur without impingement on the anterior edge of the cup. This was not. however, entirely satisfactory and so a special femoral component was designed with a truly spherical head and a more slender neck but with the same collar and stem as has a Thompson prosthesis (Fig. 3).

\section{TECHNIQUE OF OPERATION}

The operation is done on an orthopaedic table. An unsterile assistant sits at the foot of the table beneath the sterile drapes and adjusts the position of the leg as required during the course of the operation (Fig. 4). 
An antero-lateral approach is used, the incision starting at the anterior superior iliac spine, running down to the tip of the greater trochanter and then two or three inches down the femoral shaft, with a slight curve anteriorly (Fig. 5).

The interval between the tensor fasciae latae anteriorly and the gluteus minimus and medius posteriorly is opened to reveal the capsule of the hip joint, no muscles having been divided. The plane of cleavage between the muscles is most easily found distally where, after incision of the deep fascia, it is easily located by the finger. Proximally, the muscles are intimately blended and need separation by sharp dissection. Once these muscles

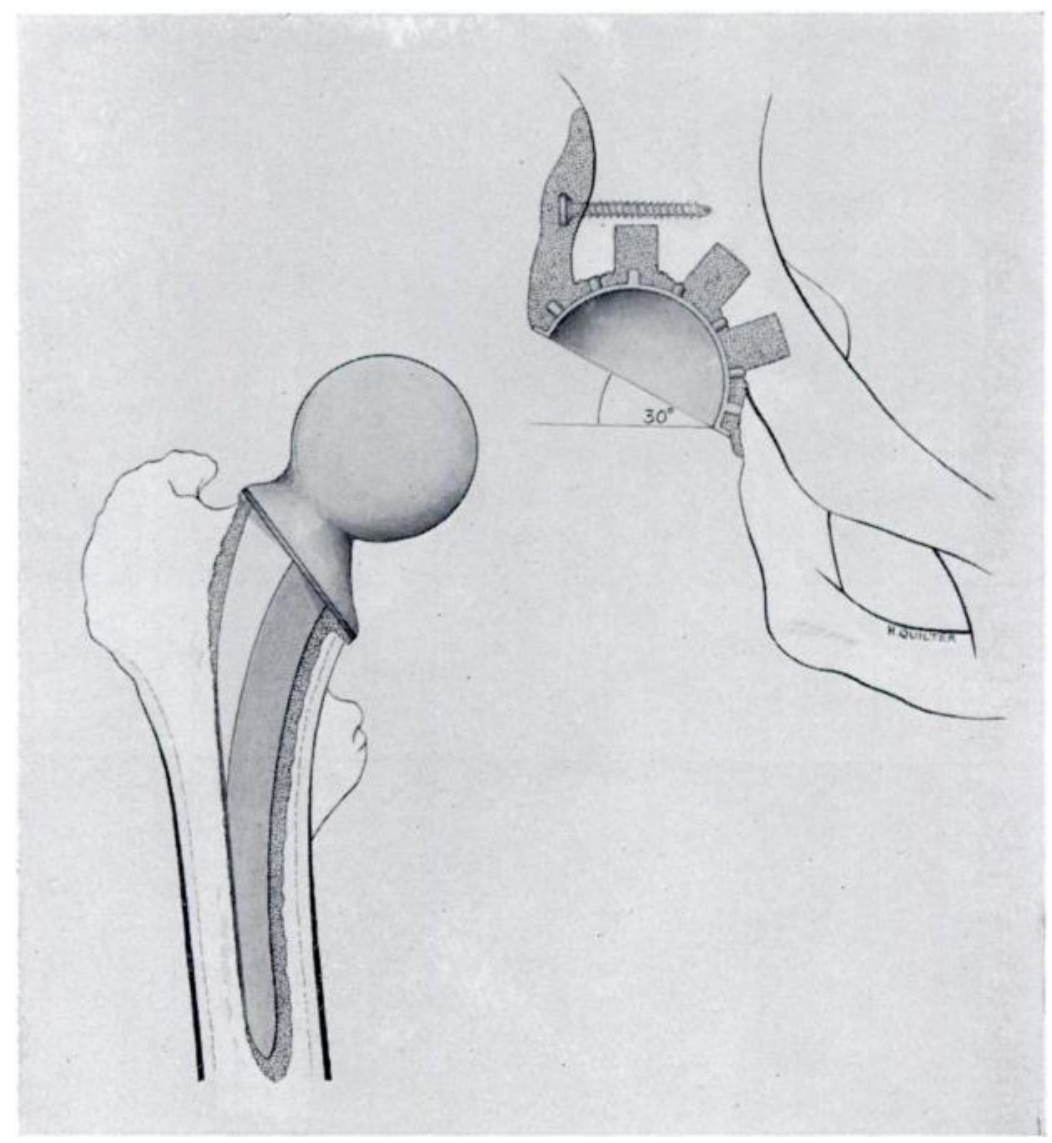

FIG. 10

A diagrammatic representation of the position and fixation of femoral and acetabular components of the artificial joint.

have been separated the outer aspect of the wing of the ilium is partly cleared of muscle attachments.

The capsule of the hip joint is now clearly visible, as is the reflected head of the rectus femoris, which is excised with the anterior half of the capsule of the hip joint (Fig. 6).

Once this has been cleared the head of the femur is dislocated. If there is much osteoarthritic lipping of the acetabulum dislocation of the femoral head is facilitated by removing some of the excess bone. If the foot is now removed from the footpiece the unsterile assistant can help to dislocate the hip by exerting traction and by laterally rotating and adducting the leg. The head and part of the neck of the femur are then removed by means of a Gigli saw (Fig. 7). This allows excellent access to the acetabulum (Fig. 8)-far better than can be obtained by a posterior approach, which is not considered suitable for this operation.

VOL. 48 B, NO. 2, MAY 1966 


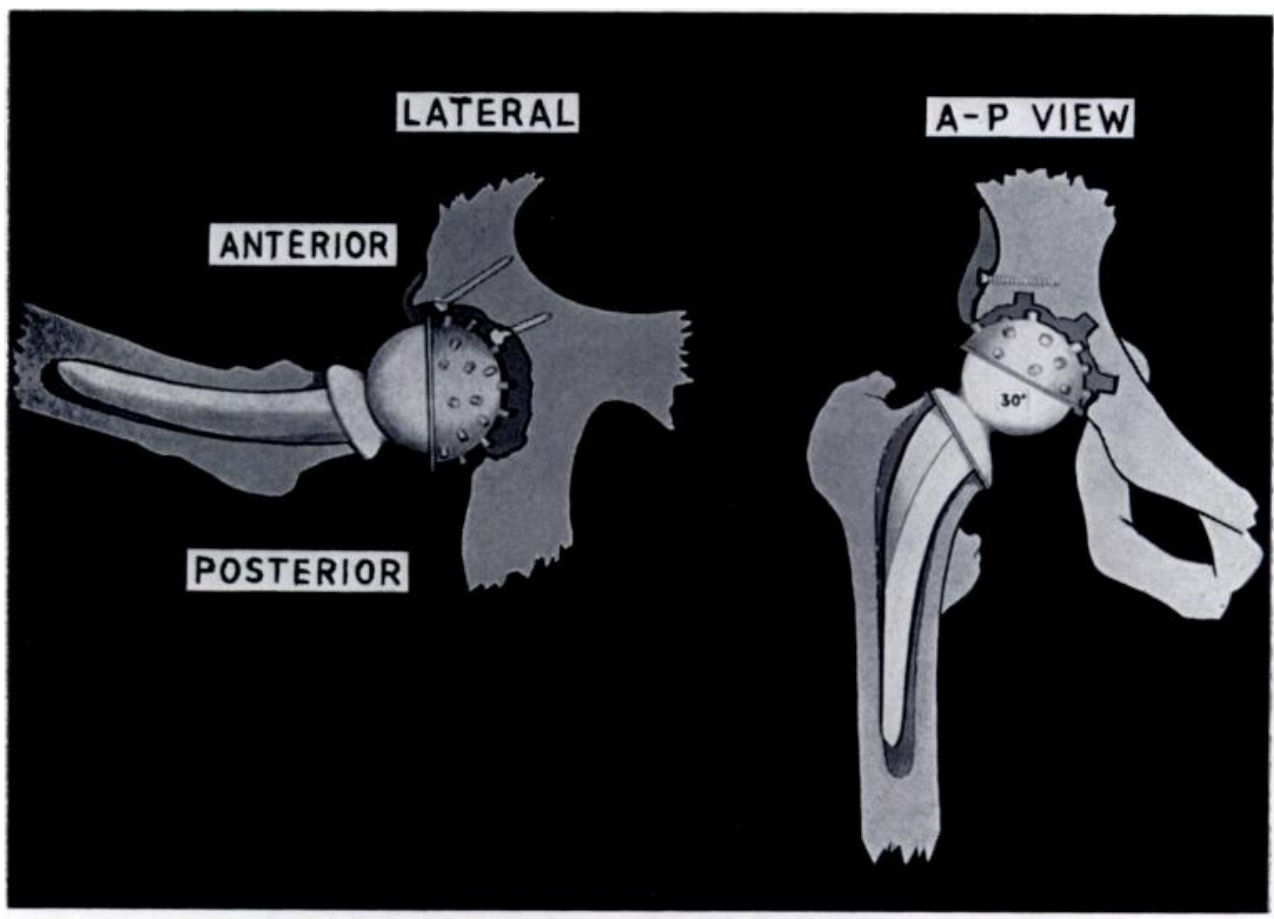

Fic. 11

Diagrams showing correct position of the cup as seen in the lateral and in the antero-posterior view.

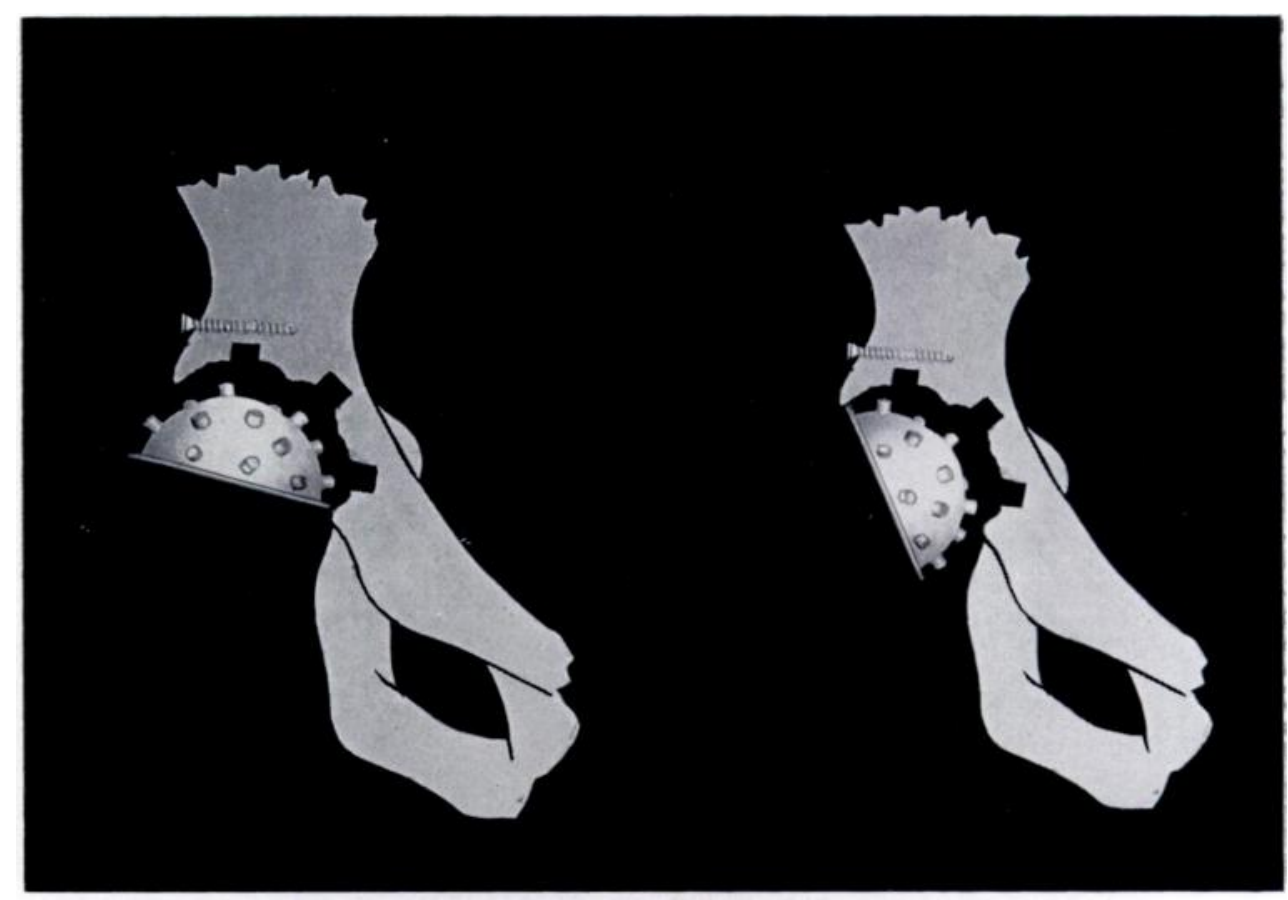

Fig. 12

Diagrams (antero-posterior view) showing the cup too closed (left) and too open (right). 


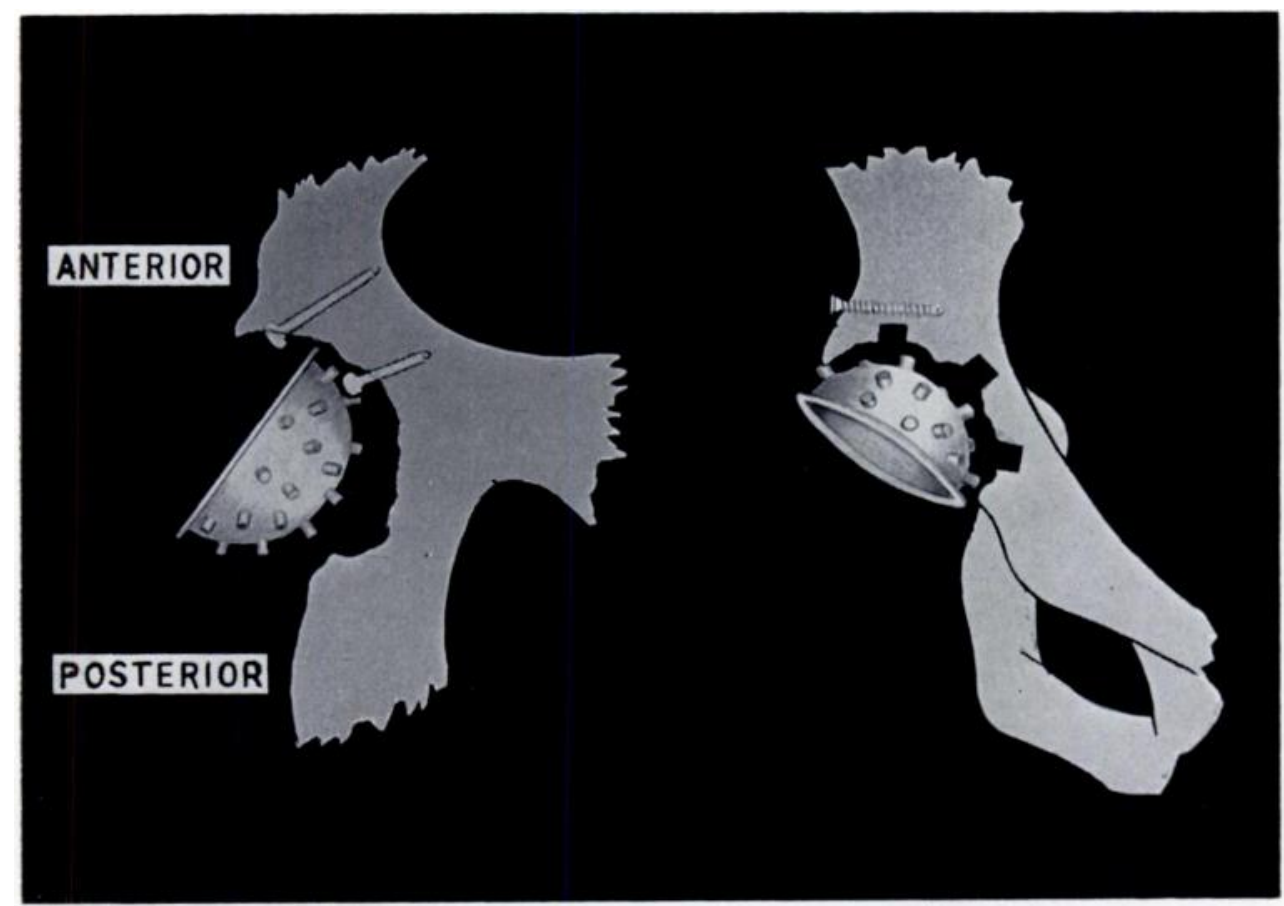

Fig. 13

Diagrams showing cup anteverted. Left is lateral view; right is antero-posterior view.

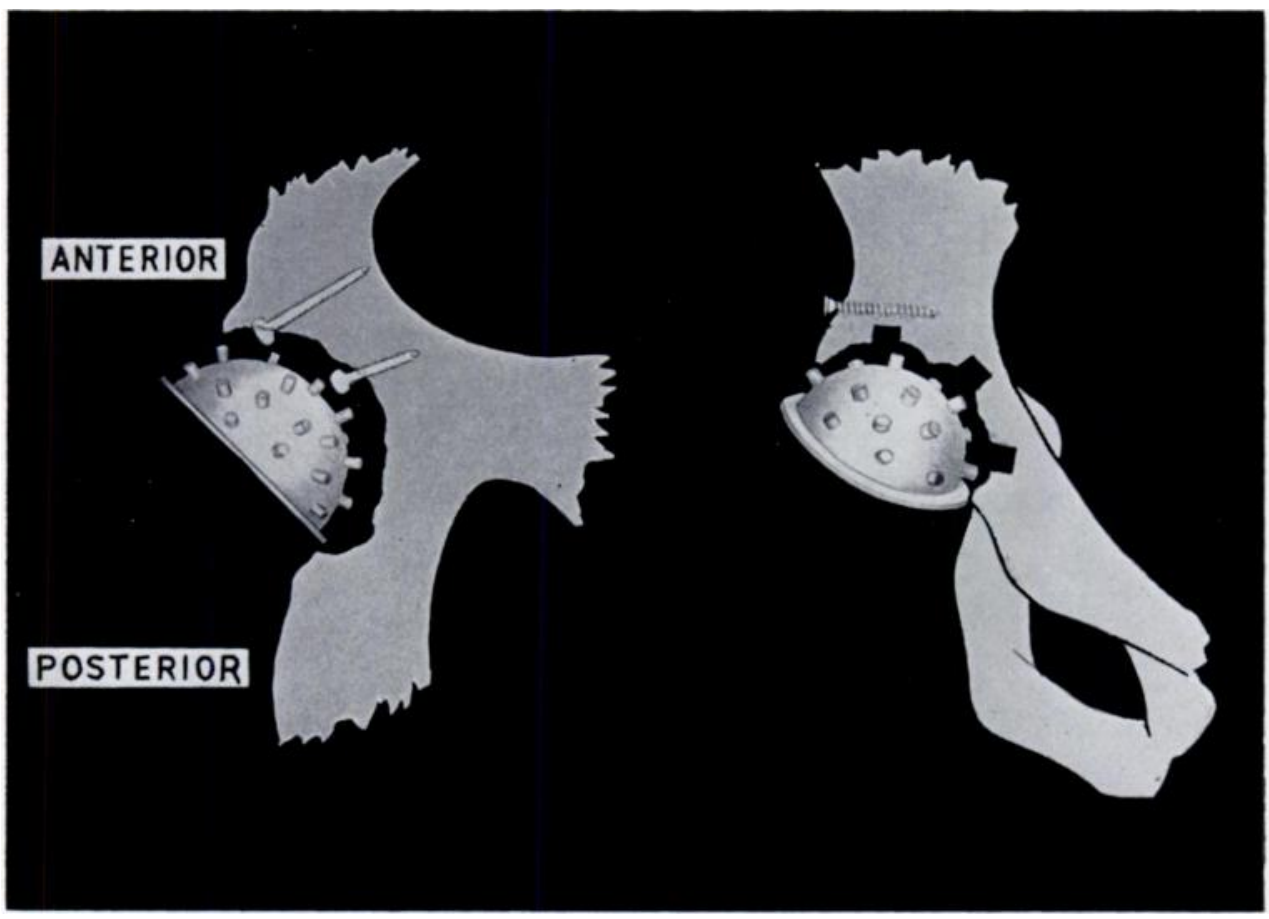

FIG. 14

Diagrams showing cup retroverted. Left is lateral view; right is antero-posterior view. 
Preparation of the acetabulum-All remnants of articular cartilage are removed from the acetabulum with a gouge. A reamer is not used because this makes the walls of the acetabulum smooth; the rougher the walls are left the better the plastic cement will key on to the bone. The soft tissue is removed from within the fovea because this depression is an excellent anchorage for the cement. For the same purpose a cavity leading towards the ischial spine is made in the ischium. Three or four holes are then drilled into the superior and supero-medial aspects of the acetabulum with a three eighths of an inch drill. The superior holes go up into the wing of the ilium, but those in the supero-medial part sometimes penetrate the inner cortex, which is of no consequence. In addition to these large holes several quarter-inch holes are always drilled wherever practicable. All of these holes are to provide anchoring points for the plastic cement. Occasionally if the bone is abnormally soft, we make fewer holes in the roof of the acetabulum so as not to weaken it too much.

The outer cortex of the ilium immediately above the acetabulum is thoroughly cleansed of soft-tissue attachments and two screws are inserted parallel to the roof of the acetabulum, to grip both outer and inner cortices of the ilium. The purpose of these screws is to provide further anchoring points for the plastic, which later is allowed to flow out of the acetabulum on to the ilium, forming a kind of plastic shelf. This completes the preparation of the acetabulum, the aim of which is to ensure that the cement will key to the bone, because it does not in any sense bond to the bone but remains tight only because of its intimate contact and the effectiveness of the key (Fig. 9).

Before proceeding it is wise to ensure that the cup is easily inserted. A shallow acetabulum should be deepened by removing bone from its supero-medial and posterior aspects. It is important that the cup sits well within the cavity because the deeper it is the more stable it will be. The acetabulum and the various holes that have been made within it are now plugged with swabs to help control oozing from the raw bone.

Preparation of the femoral neck-The femoral neck is prepared in the usual manner for the insertion of the Thompson prosthesis, care being taken to ensure that the stem of the prosthesis lies accurately within the femoral shaft and does not penetrate the cortex. To facilitate the introduction of the plastic the soft cancellous bone that lies within the remains of the neck and shaft of the femur is curetted out.

Position of the cup-With both bony regions now ready the next step is to insert the cup. The positioning of the cup is extremely important because failure to obtain the correct position in both the sagittal and transverse planes may lead to an unsatisfactory result.

The more parallel the mouth of the cup is to the sagittal plane-a position in which the cup mouth can be described as "open "- the easier it will be to reduce the dislocation, but the more unstable is the resultant joint and the easier it is to dislocate. The more the mouth of the cup is at right angles to the sagittal plane, that is, with the mouth of the cup facing distally, the more difficult will be the reduction but the more stable the arthroplasty. The best position is with the mouth of the cup inclined at about $\mathbf{3 0}$ degrees from the horizontal plane (Figs. 10 to 14$)$.

In the transverse plane the cup should be level, with its anterior edge directly anterior to its posterior edge (Figs. 15 and 17). If the mouth of the cup is inclined posteriorly the neck of the Thompson posthesis impinges on the anterior edge when the leg is flexed, causing a strain which may loosen the cup, as happened in Case 1 in this series. This strain is lessened further by the modified Thompson prosthesis already described. If the mouth of the cup is inclined too much anteriorly, there may be instability.

Insertion of the cup-To insert the cup a " mix" of the plastic cement is prepared. The plastic used is Simplex " $p$ " produced by North Hill Plastics Limited. It consists of a powder (the polymer) and a liquid (the monomer). Both are contained in sterile packs, the powder in sterile packets of forty grammes, and the fluid in ampoules of twenty millilitres, which are the correct proportions for a " mix." 
During the mixing of the cement a stage is reached after two or three minutes when the plastic dough no longer "sticks" to the surgeon's gloves. It is now ready for use and there are about three minutes during which the plastic has a soft workable consistency; thereafter it begins to get rubbery and the best time for its use has passed. In a further four or five minutes the plastic sets solid.

When the plastic is ready for use a lump is inserted into the acetabulum and pushed well up into the various holes that have been created. Some of the plastic is allowed to overflow on to the outer cortex of the ilium immediately above the rim of the acetabulum where the screws have been inserted. Usually the whole of one " mix" is needed. For very large-boned patients with deep acetabula more than one may be necessary, and it is then imperative that sufficient plastic be prepared at the same time. As soon as the plastic has been put into the acetabulum the cup is inserted in its correct position and the plastic that lies outside the acetabulum is moulded to fill the gap that lies between the outer surface of the cup and the wing of the ilium. It is brought into intimate contact with the screws, which it surrounds and covers; the heads of these screws lie about a quarter of an inch proud of the surface of the bone.

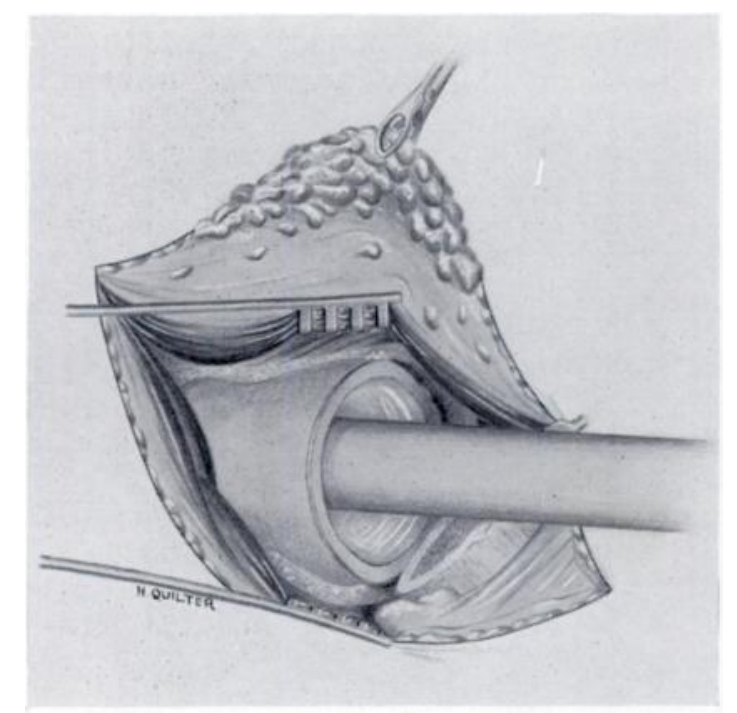

FIG. 15

The cup has been inserted and is being held in place with a blunt metal rod while the plastic cement sets. Note that the anterior edge of the cup is directly anterior to the posterior edge.

Once the position of the cup has been correctly achieved firm pressure is maintained pushing the cup into the cement with a blunt metal rod; this pressure is continued until the cement has set firmly (Fig. 15). During the few minutes that this takes to occur, care is taken to remove any cement that has flowed over the lip of the cup into its mouth because this would impede reduction of the femoral prosthesis.

Fixation of the Thompson prosthesis-With the cup firmly fixed, the prosthesis is inserted in the femoral shaft and a trial reduction made. Before this is done it is imperative that the cup is filled with swabs to prevent complete reduction because subsequent redislocation may be extremely difficult (Fig. 18). If it is obvious that reduction is impossible more femoral neck is removed or, if this is impossible because of a short femoral neck, psoas tenotomy is done. This allows the femur to be distracted further and is in effect the same as excising more femoral neck. This has been done on several occasions without any obvious alteration in the course

VOL. 48 B, NO. 2, MAY 1966

D 
after operation, but trimming the femur is preferred because this gives better control over the final tension of the joint and diminishes any tendency to dislocation after operation.

It is desirable that the actual reduction should be difficult and require some effort. The more difficult the reduction the better. There need be no worry that the arthroplasty will be too tight. If, on the other hand, reduction is very easy, stability is likely to be impaired. If reduction is just possible then an ideal amount of femoral neck has been removed. Therefore, when it is apparent that reduction will just be possible the upper part of the shaft of the femur is filled with plastic and the femoral prosthesis reinserted and allowed to set. The artificial joint is then reduced (Fig. 19); for this the unsterile assistant exerts strong traction on the leg while the surgeon pushes the new femoral head with a punch shaped to fit. At the moment when the top of the head engages with the lip of the cup pressure is exerted in a medial direction, the leg is medially rotated and the head sinks into the cup. The wound is then closed in layers. Post-operative treatment-Plaster-of-Paris immobilisation is not used unless it is considered that the joint is somewhat unstable, when a short hip spica is applied and kept on for three weeks. Normally the feet are bound together until the patient has fully recovered from the anaesthetic and until muscle tone has recovered. This is done to prevent the hip from being inadvertently dislocated from unskilled handling on returning the patient to bed.

Pain after operation is seldom troublesome and active exercises can be started on the day after operation. Usually by the end of the first week the patient can walk with crutches with partial weight bearing, but rapid progression to full weight bearing is allowed and after two weeks the patient has usually started to use sticks. Obviously the speed of progress depends to a

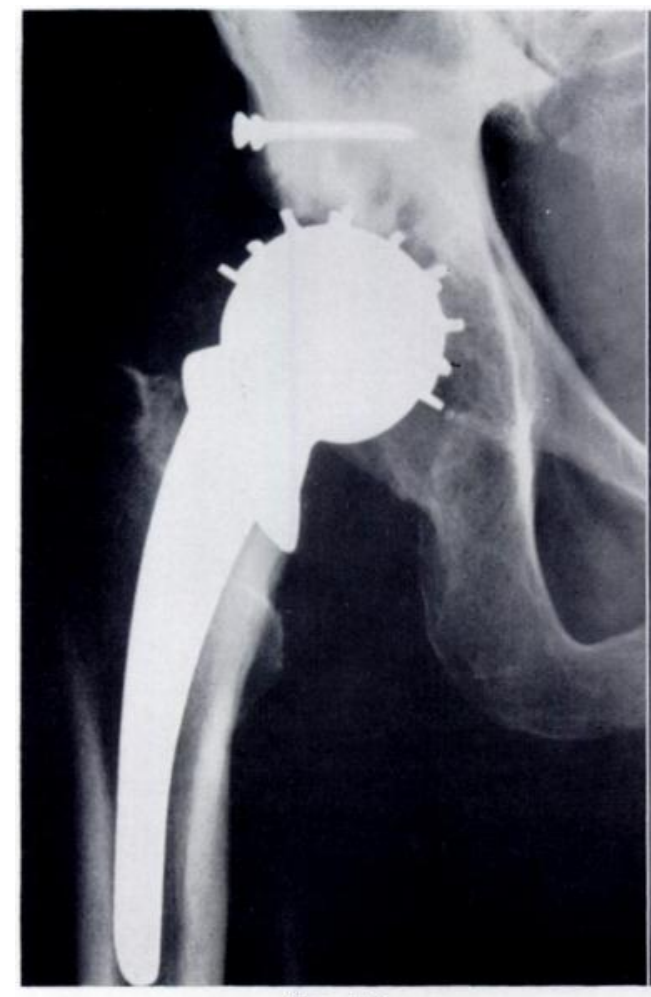

FIG. 16

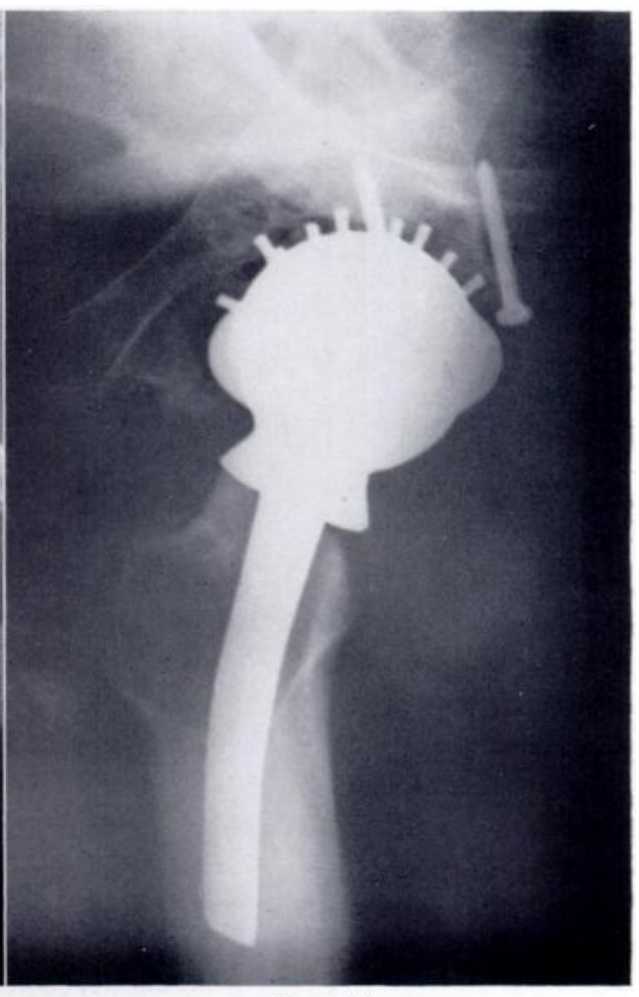

FIG. 17

Radiographs to show the position of the artificial hip joint in antero-posterior and in lateral views.

large extent upon the individual patient, but, because of the absence of pain and the lack of any muscle incision with the antero-lateral approach, progress is surprisingly rapid. The relief from pain is immediate and equal to that of arthrodesis, but there is restoration of function as well. 
The length of stay in hospital varies from two and a half to three weeks, when the patient can usually manage stairs. After discharge, physiotherapy may be continued for a further three or four weeks, by which time the patient normally can manage to walk indoors without aid.

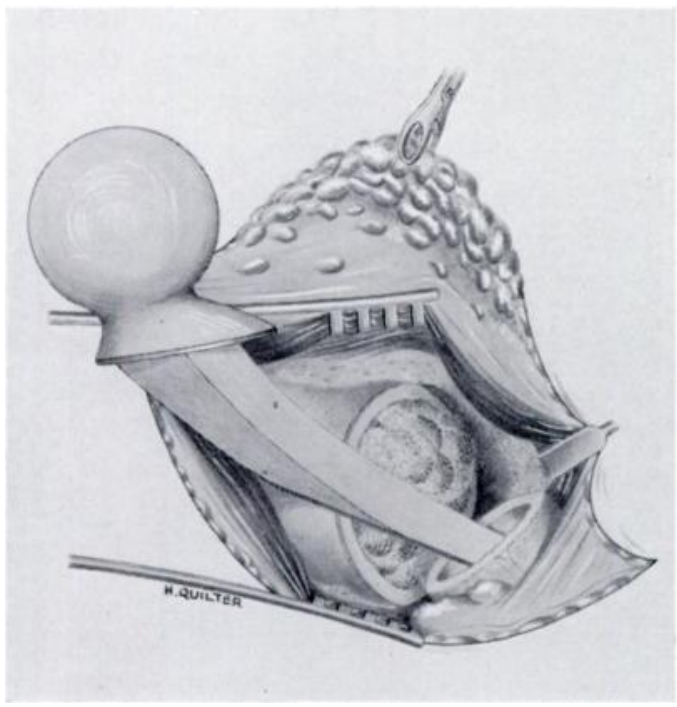

FIG. 18

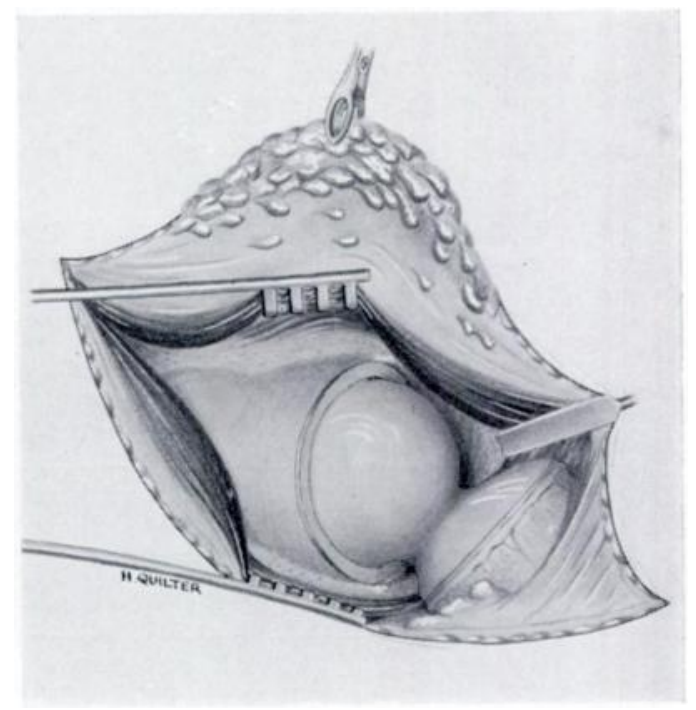

FIG. 19

Figure 18-The femoral part is being inserted for trial before reduction. Note the swabs in the cup. Figure 19The artificial joint reduced.

Physiotherapy-Physiotherapy consists simply of exercises. At first slings may be used, but after ten days the exercises are against gravity, turning on to the good side to do abduction exercises and then into the prone position to do extension exercises. Forced flexion strains are avoided because the leverage employed in doing these can put an excessive strain on the cup.

\section{RESULTS}

These have been very encouraging, and are summarised in Table I. Forty-seven of the first fifty cases had excellent or good results.

Difficulties encountered after operation-The very few difficulties met after this operation have usually been due to technical faults (Table II). Six revision operations have been done, two for incorrect positioning of the acetabular component, one for incorrect insertion of the Thompson prosthesis, two for loosening of the acetabulum after falls and one for loosening of the femoral component. All were corrected at revision.

Incorrect positioning of the cup-In Cases 1 and 32 the cup was inserted in a too vertical, or open, position. In Case 1 the under-surface of the neck of the Thompson prosthesis butted against the anterior margin of the cup on flexion; this dented the rim of the cup and ultimately fragmented and loosened it, causing pain on weight bearing after nearly two years. At the revision operation the cup and Thompson prosthesis were easily removed and a completely new joint was inserted. It was interesting that the stem of the Thompson prosthesis of the new joint fitted perfectly into the plastic bed in the shaft of the femur that had been created by the former prosthesis. This hip is now functioning well and the patient is free from pain eighteen months after the revision operation.

In Case 32 the cup was again too vertical; this led in the early stages to a tendency to subluxation of the femoral portion with pain on weight bearing. At revision the cup was found to be loose in the acetabulum and was easily removed. The Thompson prosthesis was quite easily tapped out of the femoral shaft and the same joint was reinserted with the cup in a more horizontal position. A year later the hip was very satisfactory. 
These two hips illustrate the importance of using a Thompson prosthesis instead of the Austin Moore: it would be impossible to tap the latter out of the plastic bed because of the fenestrations in its stem.

Incorrect insertion of the femoral component-In a third hip, Case 2, the stem of the Thompson prosthesis was incorrectly inserted and it penetrated the cortex of the femur at the back of the shaft. It lasted for eighteen months until the patient had a fall and it then began to give pain on weight bearing; this long interval almost certa nly was because the plastic itself did not work loose within the femur until the fall. At revision the prosthesis and its plastic bed were loose within the femur, the stem assuming a more horizontal position. Removal was easy. The upper end of the shaft was filled with new plastic and the Thompson prosthesis reinserted, this time with its stem correctly placed within the femoral shaft. This patient obtained a satisfactory

TABLE I

Results of the First Fifty Consecutive Cases done from April 1961 to December 1963

\begin{tabular}{|l|cc|}
\hline & Result & Per cent \\
\hline Excellent & $\begin{array}{c}\text { No pain, almost full movements, } \\
\text { walking almost normally, no stick }\end{array}$ & 26 \\
\hline Good. & $\begin{array}{c}\text { Free from pain, useful 50 per cent range of movement, } \\
\text { slight limp, improved with stick }\end{array}$ & 68 \\
\hline Fair & $\begin{array}{c}\text { Slight pain, small range of movement, } \\
\text { walks with two sticks }\end{array}$ & 2 \\
\hline Poor & $\begin{array}{c}\text { Slight pain, walk with two elbow crutches, } \\
\text { poor range of movement }\end{array}$ \\
\hline
\end{tabular}

TABLE II

COMPlications after Operation

\begin{tabular}{|c|c|}
\hline Death & None \\
\hline . & $\begin{array}{l}\text { Two cases, both healed with antibiotics, } \\
\text { one with mild recrudescence }\end{array}$ \\
\hline Technical faults & $\begin{array}{l}\text { Three cases, all finally good results with } \\
\text { revision operations }\end{array}$ \\
\hline $\begin{array}{l}\text { Loosening of the cup } \\
\text { after falls }\end{array}$ & Two, both treated by revision operations \\
\hline Poor result & $\begin{array}{l}\text { Loosening of the femoral portion in a very } \\
\text { heavy woman, probably because of not } \\
\text { using sufficient plastic cement }\end{array}$ \\
\hline
\end{tabular}

result. It is interesting that, at this operation, the acetabular part was rigid and there was no evidence of any reaction whatsoever between plastic and bone after eighteen months of use and weight bearing.

Loosening of the parts because of falls-This has happened twice, in Cases 19 and 24, after falls which were followed by pain on weight bearing. One patient had had a very good result for a year and then had a fall; this was followed by the gradual onset of pain on weight-bearing severe enough to warrant revision. Both acetabular and femoral components were slightly loose. They were both removed, the bone was freshened and the same parts replaced using plastic cement. The components were, if anything, a smoother and more perfect joint than when they were originally inserted and there was practically no sludge even though there had been a year of active use and weight bearing.

The other patient had had a very good hip for fifteen months and then had a fall followed by the gradual onset of pain on weight bearing. Radiographs showed that one of the screws 
in the ilium had broken; this indicated clearly that the acetabular component had been loosened. At revision the plastic cement in the acetabulum was loose in the bone, but the cup was firmly fixed in the plastic by its studs. One screw had broken and the other was loose. The femoral part was still tight in the plastic and the plastic completely firm in the bone. The prosthesis was tapped out of its bed quite easily. The bone of the acetabulum was freshened, the old holes drilled out again, two new screws inserted into the ilium and a new acetabular prosthesis cemented in. Its corresponding new femoral part was inserted in the bed of plastic from which the previous one had been removed.

Possible salvage procedures-In our first fifty cases three have caused trouble because of technical errors and two because of falls requiring a second operation, and in each case it has been possible to remove the loose component and insert a new joint with success. It seems, therefore, that the best salvage procedure is to insert a new artificial hip joint. One other possibility would be to remove the whole apparatus and leave the patient with a pseudarthrosis. So far this has not been necessary.

Sepsis-There has been very little trouble from infection in this series. One patient had a superficial infection; the upper part of the incision broke down and discharged pus. When explored under an anaesthetic the infection was found to be confined to the superficial fat. After six weeks of antibiotic treatment the wound had healed and it has remained dry since.

A second hip became infected, with a sinus tracking down into the joint. The patient was treated with massive doses of antibiotics and the sinus ultimately healed. There has been further recrudescence of this infection. Although movements are not as free as they usually are with this operation the patient is free from pain.

There were no other infections. Antibiotics were not given routinely but the wounds were insufflated with Polybactrin before closure.

Use of plaster after operation-Three patients needed plaster: the patient in Case 33 weighed 240 pounds (110 kilograms) and reduction was thought to have been unstable; in Case 32 the cup was put in too vertically and the hip dislocated; the patient in Case 15 sustained a fractured femur through the screw holes used to fix an osteotomy plate at a previous operation. Erosion of bone-In the six revision operations (Cases 1, 2, 19, 24, 29 and 32) it is interesting that a certain amount of bone erosion had taken place if the plastic had become loose in the bone.

In Cases 1 and 32, already referred to, where the acetabular plastic was loose there was some erosion of the underlying bony bed, and the longer the component had been loose the more the erosion. Here the femoral portion remained tight and there was no erosion around the plastic in the neck of the femur.

Conversely in Case 2, in which the femoral part had not been put in correctly and had become loose after a fall eighteen months after the insertion, it was found that the acetabular cup and plastic were as firm as could be and that there was no erosion.

This experience, therefore, shows that the plastic was well tolerated by bone provided it remained firm, but if it became loose movement of the plastic on the bone allowed some erosion which varied in amount with the length of time since the looseness started. In brief, the erosion is mechanical and not caused by reaction to the plastic.

The poor result-The patient in Case 29, a heavy woman, alone had a poor result. She had some pain on weight bearing and used two elbow crutches; the range of movement was less than 30 per cent. For the first nine months after operation all went well and she was pain-free; then she started to get pain in the knee and thigh on taking weight. (From experience of the earlier patients, this nearly always means that one or other of the components has become loose. This is not always obvious at first on the radiographs, but after a time a slight change in position of the cup can usually be seen, or there may be some evidence of a cavity around the plastic cement in the femur. Such cases are carefully watched because they should be revised as soon as one is sure that one or other component is loose and before excessive bone erosion occurs.)

VOL. 48 B, NO. 2, MAY 1966 
This arthroplasty was revised in January 1965 , because the pain on weight bearing had become much worse. The radiograph before operation showed evidence of a loose stem of the Thompson prosthesis, but the acetabular part appeared securely embedded. Apart from the weight of the patient there was no adequate reason for the Thompson prosthesis having become loose, and it was therefore decided to replace the Thompson by a Minneapolis prosthesis because the long ten-inch stem of the latter would give firmer fixation within the femoral shaft.

At the revision the acetabular part was firm; it had been in place for over two years and there was no evidence of any reaction to the presence of the plastic. The femoral component was very loose, the stem being loose within the plastic cement and the cement being loose within the femoral shaft. The prosthesis and old plastic cement were removed from within the femoral shaft, the cavity was scraped out and then well refilled with new plastic cement into which a Minneapolis prosthesis with a head one and five-eighths of an inch in diameter was inserted.

A possible explanation here is that insufficient plastic was inserted down the femoral shaft at the original operation. If this was the case the grip of the plastic in the bone was inadequate, allowing a certain amount of movement to occur between the plastic and bone. Once the plastic mass becomes loose mechanical erosion of bone occurs. In this case, therefore, because of the inadequate grip of the plastic, movement between the cement and femoral shaft probably occurred, to result in mechanical erosion of the bone and increasing looseness of the prosthesis. This would explain the gradual onset and progressive deterioration.

Otto pelvis-One of the first fifty patients had this condition. It presents difficulties, especially in dislocating the head and in the deepness of the acetabulum, the bone on the deep medial aspect of which is very thin. The acetabulum needs very careful preparation and more plastic than usual to fill it before inserting the cup.

Failed osteotomy-The patient in Case 15 had had an osteotomy which had failed to relieve pain. At operation the pin and plate were removed first and then the artificial hip joint inserted.

The joint was particularly difficult to reduce and the attempt was complicated by a fracture of the femur obliquely through the screw holes. The bone was osteoporotic, the patient having steroid treatment for asthma. The fracture was wired together and a plaster spica applied for three months. The patient is in the good category now, pain-free on weight bearing and with a useful range of movement.

Bilateral arthroplasty-In this series four patients had bilateral operations. One has an excellent result and it is very difficult to distinguish his gait from that of a normal person. The other three are all in the good category on both sides. All these patients asked for the second side to be done.

\section{DISCUSSION}

How long will they last?-This can only be answered by the passage of time, but experience of this and similar procedures since 1956 is encouraging. The present series has been tried now for four years with a success rate of over 90 per cent. Earlier series have shown that if the components remain tight in the bone they still work well after eight years.

Wear took place and caused much sludge formation in the earlier series, but with careful lapping-in of the components made from a very hard chrome-cobalt alloy this has been greatly reduced. Because the metal is inert, there are no undesirable effects from the sludge acting on soft tissues or bone.

Bone erosion caused by the plastic cement does not appear to take place unless it becomes loose; it is a mechanical and not a foreign body reaction. The components have only become loose in this series in six hips: three from faults, two from falls and one for no obvious reason.

We are therefore convinced that the principles of the operation are sound, but until it has been tried out for another four years we strongly advise that the operation be reserved for older persons. 
Some of the earlier operations before plastic cement was used have maintained good results for eight years; so this procedure has much to offer to elderly patients with severe osteoarthritis because it relieves pain, allows good walking and restores a useful range of movement, often sufficient to enable patients once more to put their shoes and socks on by themselves.

\section{SUMMARY}

1. The various surgical procedures in common use for the treatment of the osteoarthritic hip are briefly reviewed and compared with the operation of replacement of both the acetabulum and head of the femur by a metal prosthesis, that is, a complete artificial hip joint.

2. The development, description and technique of insertion of this artificial hip joint are given in detail.

3. The results of the first fifty cases of this operation show a success rate of over 90 per cent. The few failures are analysed in detail. The revision procedure has been the insertion of another artificial hip joint.

4. The essential details necessary for success are stressed and the indications and aims of the operation given.

We would like to record our thanks for the help we received in designing the cup to $\mathrm{Mr}$ Alan Chappel, dental surgeon to the Norwich group of hospitals, to Hunton \& Sons of Norwich for the manufacture of the prototypes, to Deloro-Stellite for producing the chrome-cobalt cups and to $\mathrm{Mr} \mathrm{A}$. W. Laxen of the London Splint Company Ltd. for his co-operation in its production. The artificial hip joints can be obtained through the London Splint Company Ltd. of 67-69 Weymouth Street, London, W.1., and the cement in sterile packs of the powder and ampoules of the liquid from North Hill Plastics, 49 Grayling Road, London. N.16. The drawings are the work of Mr H. Quilter, of North Walsham, Norfolk, to whom we are very grateful.

\section{REFERENCES}

Charnley, J. (1960): Anchorage of the Femoral Head Prosthesis to the Shaft of the Femur. Journal of Bone and Joint Surgery, 42-B, 28.

LAw, W. A. (1962): Late Results in Vitallium-Mold Arthroplasty of the Hip. Journal of Bone and Joint Surgery, 44-A, 1497.

Scales, J. T. (1964): Personal communication. 